\title{
0 que sabemos sobre a organização dos partidos políticos: uma avaliação de 100 anos de literatura
}

\author{
What we know about political parties' \\ organization: an evaluation of one \\ hundred years of literature
}

\section{Oswaldo E. do Amaral}

\section{Resumo}

Diante da importância dos partidos políticos para o funcionamento dos regimes democráticos contemporâneos, é fundamental compreender como essas organizações se estruturam e como se desenvolveram ao longo do tempo. Como as decisões são tomadas no interior dos partidos? Quais são os elementos que provocam transformações no desenho organizacional dos partidos políticos? Indagações como essas vêm sendo objeto de preocupação por parte de pesquisadores desde o início do século passado e uma longa tradição na Ciência Política foi construída desde o clássico trabalho de Michels, publicado em 1911. O objetivo deste artigo é descrever, sistematizar e discutir as principais contribuições da Ciência Política, tanto em âmbito internacional quanto nacional, para o estudo da organização dos partidos políticos. Para isso, nos concentramos nas abordagens que tratam, preferencialmente, da estrutura e do funcionamento interno e da relação com filiados e com organizações da sociedade civil.

\section{Palavras-chave}

Partidos Políticos; Partidos Políticos - Organização; Partidos Políticos - Desenvolvimento.

\begin{abstract}
Political parties have been acknowledged as essential organizations for the functioning of democratic regimes. Because of that, Political Science has developed a long tradition in analysing and explaining how these organizations work and evolved over time. Since the work of Robert Michels, published in 1911, scholars have been asking themselves the following questions: How does the decision making process work inside the parties? How and why political parties change? The main aim of this paper is to review and discuss the main contributions of Political Science, both abroad and in Brazil, to the study of party organization. In order to do that, we focus on the works that analysed the internal functioning of political parties and the relationship between parties, their members and other civil society organizations.
\end{abstract}

\section{Keywords}

Political Parties; Party Organization; Party Development. 


\section{Introdução ${ }^{1}$}

Há mais de cem anos, os estudiosos da política reconhecem a importância e a necessidade dos partidos políticos para o funcionamento dos regimes democráticos. É por meio deles que as democracias se estruturam e a competição política se organiza. Embora exista muita divergência sobre como as agremiações políticas funcionam e se comportam, há praticamente um consenso em torno de sua importância para a viabilidade das democracias representativas. Nesse sentido, ainda no final do século XIX, James Bryce concluiu o seguinte: "Os partidos são inevitáveis. Nenhum país livre não conta com eles. Ninguém até agora demonstrou como os governos representativos podem funcionar sem eles. Eles ordenam o caos para a multidão de eleitores" (BRYCE apud WHITE, 2006, p. 7).

A estreita ligação apontada pela Ciência Política entre os partidos políticos e o funcionamento da democracia representativa deriva das funções que as agremiações desempenham. É possível, de forma simplificada, indicarmos ao menos três funções essenciais: a) Estruturar a competição eleitoral; b) Agregar interesses; c) Governar e conduzir os trabalhos legislativos.

Diante da inegável relevância dos partidos políticos para o funcionamento dos regimes democráticos contemporâneos, é fundamental compreender como essas organizações se estruturam e como se desenvolveram ao longo do tempo. Como as decisões são tomadas no interior dos partidos? Como agem as lideranças partidárias? Quais são as relações entre os partidos e seus membros? Quais são os elementos que provocam transformações no desenho organizacional dos partidos políticos? Indagações como essas vêm sendo objeto de preocupação por parte de pesquisadores desde o início do século passado e uma longa tradição na Ciência Política foi construída desde a clássica obra de Robert Michels [1911]. Apesar da quantidade de trabalhos e abordagens, os estudos sobre a organização dos partidos não seguiram uma trajetória uniforme e ainda há muitas lacunas a preencher. No caso brasileiro, o cenário não é diferente. Apesar de muitas monografias de boa qualidade sobre diversas agremiações e alguns trabalhos com abordagem comparativa, muitos aspectos da organização dos partidos políticos ainda não receberam o devido tratamento científico.

O objetivo deste artigo é descrever, sistematizar e discutir as principais contribuições da Ciência Política, tanto em âmbito internacional quanto nacional, para o estudo da organização dos partidos políticos. Para isso, nos concentramos nas abordagens que tratam, preferencialmente, da estrutura, do funcionamento interno e da relação dos partidos com seus filiados e com organizações da sociedade civil. O texto está organizado da seguinte forma: na primeira seção, apresentamos os trabalhos clássicos da área, as questões que levantaram e as

\footnotetext{
${ }^{1}$ Parte da pesquisa em que se baseia este artigo foi feita para a tese de doutoramento "As mudanças na organização interna do Partido dos Trabalhadores entre 1995 e 2009”, em especial para os capítulos 1 e 4 . A tese foi elaborada no Programa de Pós-Graduação em Ciência Política da Unicamp e concluída em dezembro de 2010.
} 
respostas encontradas. Prestamos especial atenção à construção de tipologias e modelos partidários e às análises sobre transformações organizativas das agremiações políticas. Na segunda, avaliamos contribuições mais contemporâneas e o seu diálogo com as abordagens mais tradicionais. Na terceira, tratamos de alguns temas que vêm mobilizando a literatura internacional nos últimos anos, como os processos de seleção de lideranças partidárias e o relacionamento das agremiações com filiados e organizações da sociedade civil. Por fim, discutimos os trabalhos sobre a organização dos partidos políticos no Brasil e concluímos o texto apontando lacunas que precisam ser preenchidas e propondo uma agenda de pesquisa voltada para o caso brasileiro.

\section{Os trabalhos clássicos e os modelos de partidos}

É praticamente impossível iniciar qualquer revisão da literatura clássica sobre partidos políticos sem começar pela obra de Robert Michels [1911], Sociologia dos Partidos Políticos (1982). O trabalho de Michels suplanta a área de estudos partidários e serve de base para pesquisas sobre a organização e a distribuição de poder no interior das agremiações políticas até os dias de hoje. Influenciado por autores como Ostrogorski, Mosca e Pareto, Michels, ao analisar o Partido Social-Democrata alemão (SPD), defende que qualquer partido, mesmo os democráticos na sua origem, tende a desenvolver uma estrutura burocrática centralizada e a oligarquização de sua direção. Essa tendência, conhecida como a "Lei de Michels", ou "Lei de Ferro da Oligarquia", foi assim resumida pelo autor:

[...] A lei sociológica fundamental que rege inelutavelmente os partidos políticos [...] pode ser formulada assim: a organização é a fonte de onde nasce a dominação dos eleitos sobre os eleitores, dos mandatários sobre os mandantes, dos delegados sobre os que os delegam. Quem diz organização, diz oligarquia (MICHELS, 1982, p. 238).

Segundo o autor, a incapacidade das massas em se dirigir aliada às exigências técnico-administrativas de uma organização complexa como um partido político leva ao desenvolvimento de uma estrutura altamente burocratizada, comandada por um conjunto de dirigentes profissionais muito mais preocupados com a manutenção de suas posições internamente e com a sobrevivência da organização, do que com os objetivos políticos que inspiraram a sua criação. Como consequência, decorre uma autonomização da liderança com relação às bases partidárias e uma flexibilização dos princípios ideológicos e programáticos da agremiação. A "Lei de Ferro" elaborada por Michels traduz a interpretação teórica de que o desenvolvimento dos partidos políticos não é compatível com a manutenção de estruturas democráticas e de controle de seus líderes por parte dos filiados e, mais importante, de que as massas são capazes, apenas, de substituir antigas por novas elites. 
No início dos anos 1950, Maurice Duverger, na obra Os Partidos Políticos (1980), retomou algumas das preocupações teóricas de Michels, como a natureza das organizações partidárias, em um trabalho que se transfomou em um clássico e influenciou boa parte do debate e da agenda de pesquisa sobre os partidos políticos na segunda metade do século XX. Duverger foi o primeiro a tentar sistematizar a diversidade partidária por meio da elaboração de uma tipologia e a esboçar uma teoria geral dos partidos políticos. Entre as inúmeras contribuições do autor, destaca-se a compreensão de que tanto a origem do partido quanto a sua ideologia devem ser usadas como variáveis explicativas no tratamento da organização, desenvolvimento e comportamento dos partidos políticos.

A partir de uma análise comparativa de partidos da Europa Ocidental que combina elementos históricos, ideológicos e organizacionais, Duverger desenvolve uma tipologia dos partidos políticos que resulta, como veremos adiante, em considerações normativas por parte do autor a respeito das próprias agremiações políticas e das possibilidades de seu desenvolvimento em democracias de massa. Entre os tipos construídos por Duverger destacam-se o partido de quadros e o partido de massa.

$\mathrm{O}$ primeiro diz respeito às agremiações de notáveis formadas no século XIX e que sobreviviam no século XX especialmente sob a forma de partidos conservadores e liberais. Vejamos algumas de suas características centrais: a) origem interna ao parlamento; b) organização interna de baixa intensidade; c) fraca articulação estrutural entre as instâncias organizacionais; d) estrutura nacional descentralizada; e) ausência de critérios claros de adesão; f) financiamento partidário dependente de alguns grandes doadores privados; g) concentração do poder decisório nas mãos da elite parlamentar (DUVERGER, 1980).

A expansão do sufrágio na segunda metade do século XIX e início do século XX e a incorporação de um grande contingente de pessoas à cena política foram determinantes, segundo Duverger, para o surgimento dos partidos de massa. A expansão do sufrágio levou ao desenvolvimento dos partidos socialistas e comunistas, que, por estarem mais próximos da concepção marxista de partidoclasse, acabaram por desenvolver mecanismos para a integração dos grandes contingentes de trabalhadores característicos dos partidos de massa. Nesse ponto, fica evidente a identificação feita por Duverger entre ideologia e organização partidária (DUVERGER, 1980), posteriormente comprovada pelo trabalho de Janda e King (1985). Para o autor, os partidos de massa contam com as seguintes características: a) origem extraparlamentar; b) organização interna de alta intensidade; c) forte articulação estrutural entre as instâncias partidárias; d) rigorosos requisitos de filiação; e) financiamento compartilhado entre os membros do partido; f) forte doutrinarismo; g) subordinação dos parlamentares ao partido (DUVERGER, 1980). 
A distinção e a caracterização elaboradas por Duverger fizeram com que o autor definisse o partido de massa como o modelo de partido mais adaptado às condições impostas pela democracia moderna. Para o autor, a superioridade dos partidos de massa provocaria um processo de adaptação por parte dos arcaicos partidos de quadros, que, aos poucos, se veriam forçados a adotar algumas das características organizacionais de seus concorrentes mais modernos, em um processo descrito como de "contágio pela esquerda" (DUVERGER, 1980; WARE, 1996; HARMEL, 2002; WOLINETZ, 2002).

Nos anos 1960, a visão predominante na literatura de que os elementos centrais dos partidos de massa se universalizariam passa a ser questionada pelos estudiosos dos partidos políticos a partir da observação das transformações organizacionais e comportamentais de algumas agremiações na Europa Ocidental. O primeiro a tentar sistematizar essas transformações e propor um novo modelo, mais apto a explicar as novas características dos partidos políticos, foi Kirchheimer (1966), em uma série de artigos nos quais desenvolveu o conceito de partido catch all. Segundo o autor, a combinação entre crescimento econômico e amadurecimento do Estado de Bem-Estar provocou uma redução na polarização social e política, diminuindo a importância tanto da ideologia quanto das distinções de classe na cena partidária. Acompanhando as mudanças sociais mais amplas na Europa Ocidental, os partidos de massa estavam gradualmente transformando-se em agremiações diluídas ideologicamente, com apelos genéricos a todos os grupos sociais e cada vez mais voltadas para o sucesso eleitoral. As proposições de Kirchheimer (1966) representaram uma inversão com relação à hipótese de Duverger (1980) sobre o desenvolvimento dos partidos políticos, como é possível observar a partir das características do partido de tipo catch all: a) desideologização do discurso partidário; b) fortalecimento da liderança; c) declínio da importância da militância de base; d) apelo eleitoral pluriclassista; e) abertura para grupos de interesse variados (KIRCHHEIMER, 1966).

Nos anos 1980, Angelo Panebianco (2005) retomou a preocupação com a organização partidária em um trabalho que combina, como variáveis para compreender o desenvolvimento organizativo dos partidos políticos, o modelo genético e o grau de institucionalização das agremiações. O modelo genético pode ser determinado a partir de três fatores:

a) $\mathrm{O}$ desenvolvimento da organização partidária a partir da penetração territorial, quando um centro controla a expansão para a periferia (formação de associações locais e intermediárias do partido); da difusão territorial, quando a expansão acontece espontaneamente por ação das elites locais, que posteriormente se unem a uma organização nacional; ou da combinação dos dois processos;

b) Presença ou não de uma instituição externa que legitime o partido (igreja, sindicato, etc.). A partir dessa característica originária é possível 
distinguir os partidos entre aqueles de legitimação interna e de legitimação externa;

c) Caráter carismático ou não do partido, que pode ser verificado a partir da identificação da agremiação como um veículo construído para a afirmação de uma liderança carismática (PANEBIANCO, 2005).

Por institucionalização, Panebianco (2005) entende o processo de estabilização da organização, no qual esta deixa de ser um instrumento para a realização de determinados objetivos por parte dos filiados e passa a ter valor em si mesma. Seus objetivos não são mais separáveis ou distinguíveis da própria organização, que transita então de um sistema de solidariedade, em que predominam os incentivos coletivos e a ideologia é manifesta (objetivos explícitos e coerentes), para um sistema de interesses, em que sobressaem os interesses seletivos e a ideologia é latente (objetivos vagos e contraditórios) (PANEBIANCO, 2005). O processo de institucionalização pode ser medido em duas dimensões: a) o grau de autonomia em relação ao ambiente, entendida como a capacidade do partido em controlar os recursos necessários para o seu funcionamento; e b) o grau de sistemicidade, compreendida como a coerência estrutural interna do partido (PANEBIANCO, 2005).

O modelo desenvolvido por Panebianco (2005) busca fornecer uma teoria geral a respeito da organização dos partidos políticos, permitindo a construção de tipologias diversas de acordo com a combinação entre as variáveis descritas. A partir do seu quadro teórico, o autor levanta hipóteses explicativas para as transformações dos partidos políticos e realiza uma importante requalificação do modelo de partido catch all.

Panebianco concorda com a proposição geral de Kirchheimer (1966) de que os partidos de massa estariam caminhando para um modelo de partido catch all. No entanto, exatamente por se concentrar em questões organizativas, o autor ressalta a progressiva profissionalização das agremiações causada pelo aumento da influência dos especialistas dotados de conhecimentos técnicos. Daí a requalificação dos partidos de tipo catch all como profissionais-eleitorais. As principais características desse modelo de partido são: a) papel central exercido pelos profissionais; b) eleitoralismo, laços organizativos verticais fracos; c) predominância dos representantes públicos; d) financiamento por meio de grupos de interesse e fundos públicos; e) ênfase em questões de amplo apelo eleitoral (PANEBIANCO, 2005).

As causas das transformações dos partidos mais próximos ao modelo burocrático de massa ${ }^{2}$ em agremiações mais próximas ao modelo profissionaleleitoral encontram-se no ambiente em que estão inseridos. Segundo essa avaliação, duas mudanças ambientais estariam na origem das transformações partidárias: a primeira delas é mais estrutural e está ligada à própria dinâmica do

\footnotetext{
${ }^{2} \mathrm{O}$ modelo burocrático de massa definido por Panebianco em pouco difere das especificações feitas por Duverger (1980).
} 
desenvolvimento capitalista contemporâneo, que afetou os sistemas de estratificação social (redução de trabalhadores no setor secundário, ampliação do segmento de serviços, etc.) e a forma de inserção política dos diferentes grupos ocupacionais. As alterações estruturais repercutem então sobre os partidos ao modificar cenários políticos e as características sociais do eleitorado. A segunda mudança está vinculada à reestruturação da comunicação política sob o impacto dos meios de comunicação de massa. De acordo com o autor, "mudam-se as técnicas de propaganda e isso leva a um terremoto organizativo: os antigos papéis burocráticos perdem terreno como instrumentos de organização de consenso; novas figuras profissionais adquirem um peso crescente" (PANEBIANCO, 2005, p. 518). Já a intensidade e a velocidade das transformações estariam ligadas tanto ao nível de institucionalização do partido quanto à natureza do sistema partidário. Para concluirmos, é necessário lembrar que Panebianco afirma ser muito comum a sobreposição das características dos modelos, o que provoca tensões e conflitos internos nos partidos (PANEBIANCO, 2005).

Em meados dos anos 1990, Katz e Mair (1994; 1995) fizeram uma significativa contribuição aos estudos partidários a partir de uma dupla crítica à literatura existente e às agendas de pesquisa que tratavam os partidos de forma comparada. Primeiro, propuseram a mudança de enfoque nos estudos partidários das relações entre as agremiações e a sociedade para as relações entre os partidos e o Estado. Segundo, afirmaram que as análises dos partidos políticos ainda estavam presas a concepções antigas, como a de partido de massa, apontado como modelo ideal de organização partidária. Esse duplo equívoco, na visão dos autores, era responsável pelo diagnóstico crescente na literatura de que os partidos políticos estavam em declínio e pela incapacidade dos estudiosos em enxergar, especialmente na Europa Ocidental, as recentes transformações partidárias diante de novos desafios ambientais. Como resposta às limitações teóricas que encontraram, Katz e Mair (1995) identificaram a emergência de um novo modelo de partido nas democracias contemporâneas, o partido cartel. Esse novo tipo de partido seria o resultado de uma linha evolutiva caracterizada pelos modelos de partido de quadros, massas e catch all.

$\mathrm{O}$ que define o partido cartel são as suas relações com o Estado, apontadas como essenciais para a aquisição de recursos necessários para a sobrevivência da organização. Os principais indicadores dessa relação de dependência com o Estado são:

a) A garantia de acesso a meios de comunicação de massa, especialmente à televisão, proporcionada pelo Estado por meio de regulamentação ou cessão direta em canais estatais para a comunicação com o eleitorado;

b) $\mathrm{O}$ Estado é um importante mantenedor dos recursos humanos à disposição dos partidos. Assessores de parlamentares e membros do Executivo são pagos com recursos estatais e os funcionários do partido são 
mantidos, em grande medida, graças a repasses financeiros provenientes do Estado;

c) A atividade e a organização partidárias são cada vez mais moldadas a partir da regulamentação estabelecida pelo Estado;

d) O Estado confere legitimidade aos partidos políticos perante a sociedade civil quando estes ocupam cargos públicos;

e) Os partidos utilizam recursos estatais para a distribuição de incentivos seletivos a seus membros ou grupos sociais que os apoiam (patronagem partidária) (MAIR, 1994).

O estreitamento dos laços dos partidos com o Estado tem algumas consequências importantes para a prática democrática e para a disputa interpartidária. A emergência do partido cartel opera uma significativa inversão na relação entre Estado, partidos e sociedade civil. Durante a prevalência dos modelos de partidos de massa e catch all, as agremiações agiam como intermediárias dos interesses da sociedade civil junto ao Estado. Agora, é o Estado que atua como intermediário entre os partidos e a sociedade civil (MAIR, 1994). Com relação à disputa interpartidária, o modelo de partido cartel estabelece que, mais relevante do que vencer eleições, é garantir o acesso aos recursos estatais vitais para a sobrevivência das organizações. Dessa forma, interessam aos partidos mais importantes tanto a cooperação para a manutenção dos canais de financiamento do Estado quanto o bloqueio da ascensão de outsiders por meio de restrições legais (KATZ e MAIR, 1995).

Ainda de acordo com Katz e Mair, fatores sociais, culturais e políticos, além das próprias características dos partidos de tipo catch all, foram os responsáveis pela emergência desse novo tipo partidário. $\mathrm{O}$ declínio nos níveis de participação da população nas atividades partidárias, a maior volatilidade do eleitorado e o crescente distanciamento com relação às bases partidárias fizeram com que as agremiações políticas estreitassem seus vínculos com o Estado. Esse é um aspecto importante da proposição teórica dos autores, pois, para eles, a evolução dos partidos políticos nas democracias ocidentais é reflexo de um processo dialético, no qual cada novo tipo de partido produz uma série de reações que estimulam seu próprio desenvolvimento e o surgimento de um novo modelo (KATZ e MAIR, 1995).

As inovações teóricas de Katz e Mair sugerem uma requalificação mais ampla no estudo dos partidos políticos. No lugar de falarmos em declínio e fracasso, deveríamos falar em adaptação e mudança (KATZ e MAIR, 1995). Essa requalificação fica mais fácil de ser compreendida quando se observam os partidos políticos não como unidades organizacionais indivisíveis, mas sim portadores de três faces distintas que interagem entre si e contam com estruturas próprias de recursos, oportunidades, incentivos e restrições. Vejamos: a) Party in public office, a face pública do partido, representada pela organização no governo ou no parlamento; b) Party on the ground, a base partidária, composta pelos 
militantes e filiados e, de uma maneira mais ampla, por contribuintes e eleitores fiéis; c) Party in central office, a direção nacional do partido, composta tanto pelos principais dirigentes partidários, como membros de diretórios e executivas nacionais, quanto pelo alto escalão da burocracia partidária (KATZ e MAIR, 1993).

A ruptura com a visão unitária de partido político permite a Katz e Mair (1993, 1995, 2002) qualificar os diferentes tipos partidários e entender suas mudanças a partir da interação - e das relações de poder - entre as várias faces. Para os autores, o partido de tipo catch all pode ser também caracterizado por uma peculiar condição de conflito entre a base e a face pública da agremiação. Ambas buscam, por meio da direção partidária, subordinar a outra. Já as organizações partidárias contemporâneas, mais próximas do modelo de partido cartel, apresentam uma posição privilegiada da face pública ante as outras duas. Nas palavras dos autores:

[...] Sugerimos que o desenvolvimento das organizações partidárias na Europa ultrapassou o período do partido catch all e entrou em uma nova fase, na qual os partidos encontram-se cada vez mais dominados [...] pela face pública do partido (KATZ e MAIR, 2002, p. 122).

\section{Os novos caminhos}

Mais recentemente, alguns autores reavaliaram, de forma crítica, a literatura a respeito dos tipos partidários, bem como os fatores responsáveis por provocar mudanças organizativas nas agremiações. Para Wolinetz (2002), o estudo comparado dos partidos políticos, apesar de conter uma rica tradição e literatura, não foi capaz de gerar avanços teóricos relevantes nos últimos anos por se basear em tipos ideais incapazes de lidar com a multiplicidade de características que os partidos adquiriram após a "Terceira Onda de Democratização" e por não se preocupar em construir critérios de análise que unificassem as abordagens existentes.

Partindo dessa dupla crítica à literatura existente, o autor buscou elaborar uma nova tipologia, capaz de romper com as barreiras entre as tradições sociológica, funcionalista e organizativa no estudo dos partidos, possibilitando a comparação e a avaliação das agremiações tanto historicamente quanto em diferentes regiões, rompendo com a centralidade dos modelos construídos exclusivamente a partir da experiência democrática européia. Sua principal variável de análise está vinculada ao comportamento dos partidos, e a distinção que estabelece dá-se entre partidos de tipo policy-seeking, vote-seeking e officeseeking. Derivando sua tipologia dos trabalhos de Strom (1990), Harmel e Janda (1994) e Strom e Muller (1999), o autor elenca as seguintes vantagens na adoção desse modelo de análise, conforme apontamos em outro trabalho: 
a) é mais flexível e não aponta um sentido único na evolução das agremiações. Os partidos podem caminhar em sentido a um tipo ideal ou a outro ao longo do tempo e sob diferentes circunstâncias; b) permite a compreensão dos partidos como organizações que podem possuir características de mais de um tipo ideal em vários graus; c) possibilita o estudo da disputa interna de poder. É possível usar a mesma classificação para analisar os grupos internos e como eles influenciam o partido; d) com o refinamento da operacionalização, permite a análise tanto do comportamento quanto da organização das agremiações; e) com definições claras e boas medidas operacionais, é possível comparar partidos em diferentes lugares e contextos.

$\mathrm{O}$ tipo de partido policy-seeking é aquele que possui programas bem definidos, ideologias articuladas e que busca remodelar a agenda política com o objetivo de realizar mudanças substantivas em uma série de áreas. Geralmente, o partido dá mais prioridade às suas ideias e a seu programa do que às eleições. No aspecto organizacional, conta com intensa participação de filiados/ativistas na vida partidária e com uma infraestrutura de apoio para o desenvolvimento de políticas. $\mathrm{O}$ tipo vote-seeking, por sua vez, é aquele cujo principal objetivo é vencer eleições. Seu programa é mais maleável e pode ser mais facilmente alterado para maximizar as possibilidades de vitória eleitoral. O nível de envolvimento dos filiados na vida partidária é baixo, a estrutura partidária não é grande e as campanhas eleitorais são altamente profissionalizadas. Já o partido office-seeking é aquele que prioriza participar do governo, pois dessa participação muitas vezes depende a sua própria sobrevivência. Evita comprometimentos programáticos que dificultem alianças políticas e busca conseguir votos suficientes para participar de coalizões governamentais. Seus membros ocupam - ou buscam ocupar - cargos públicos e disputam acesso aos recursos provenientes do Estado (AMARAL, 2010, p. 112113).

Wolinetz (2002) critica também a unidirecionalidade presente nos trabalhos de Duverger (1980), Kirchheimer (1966), Panebianco (2005) e Katz e Mair (1995), entre outros. Para o autor, assim como para Ware (1996) e Krouwel (2006), é impossível afirmar que exista uma tendência homogeneizante na evolução dos partidos políticos. Pressões ambientais variadas, como um determinado panorama socioeconômico ou contexto institucional, combinadas com as características internas dos partidos e o comportamento de suas lideranças, podem, por exemplo, produzir transformações distintas em partidos com características semelhantes. Nesse sentido, mais importante do que determinar as tendências evolutivas nos partidos políticos, seria descobrir as variáveis que provocam as transformações partidárias.

Encerramos esta seção com a recente contribuição de Samuels e Shugart (2010) sobre como diferentes desenhos institucionais exercem influência sobre a organização dos partidos políticos. Segundo os autores, a dominância da literatura europeia na área fez com que uma importante variável institucional - o sistema de governo - tenha ficado ausente das análises sobre organização partidária. Para os 
autores, a literatura europeia privilegiou variáveis socioeconômicas e macrocontextuais para o tratamento da organização dos partidos políticos, negligenciando como a separação de poderes pode afetar as agremiações políticas. Mesmo com o aumento de países com presidentes eleitos nas últimas décadas no continente europeu, essa variável continuou a ser ignorada pela maioria dos estudos partidários.

Para os autores, sistemas presidencialistas favorecem a criação de partidos "presidencializados". Ou seja, a separação dos poderes Executivo e Legislativo constitui uma estrutura de incentivos e oportunidades distinta da encontrada em sistemas parlamentaristas para a organização e atuação dos partidos políticos. Samuels e Shugart (2010) sugerem que a possibilidade de escolha do presidente da República em uma eleição direta e a sua manutenção no poder independentemente do Parlamento tornam os partidos políticos menos capazes de controlarem suas lideranças, que adquirem maior autonomia com relação à base partidária. Além disso, a existência de duas lógicas eleitorais distintas (uma para o Executivo e outra para o Legislativo) aumenta a possibilidade de conflitos intrapartidários, pois a seleção de candidatos e a condução de campanhas eleitorais em um cenário presidencialista pode colocar em rota de colisão postulantes à presidência e lideranças partidárias e candidatos ao Legislativo.

Samuels e Shugart (2010) não descartam a importância de variáveis sociais, culturais e econômicas para a compreensão das distintas formas organizativas adquiridas pelos partidos políticos, mas chamam a atenção para um elemento que consideram ausente. Ao fazerem isso, abrem novas possibilidades de pesquisa especialmente no âmbito da política comparada.

\section{0 que sabemos sobre filiados, relações com organizações da sociedade civil e processo decisório interno}

Como foi possível vermos até aqui, existe uma série de possibilidades para abordar a organização dos partidos políticos. Seria impossível, neste texto, tratar de todas elas de maneira sistemática. Dessa forma, optamos, nesta seção, por apresentarmos o que a literatura internacional vem discutindo em torno de três temas: a) relação com filiados; b) relação com organizações da sociedade civil; e c) processo decisório interno.

A análise da relação dos partidos políticos com seus filiados esbarra em um problema de natureza empírica: a coleta de dados sobre os membros. Nem sempre esses dados estão disponíveis ou apresentam a precisão desejada pelos pesquisadores. As duas técnicas mais comuns para a obtenção de dados a esse respeito são a análise dos registros fornecidos pelos partidos políticos e a utilização de informações obtidas em surveys. Com relação a primeira, é comum a superestimação do número por parte dos partidos para fins políticos ou mesmo de propaganda. Apesar disso, a maior profissionalização das agremiações e o desenvolvimento de sistemas de informação mais sofisticados nas últimas décadas 
ampliaram a confiabilidade dos números. Com relação a segunda, os entrevistados podem não se lembrar que são filiados ou sentirem-se constrangidos a declarar participação. A melhor estratégia parece ser combinar os dois tipos de dados, conforme sugerem Van Biezen, Mair e Poguntke (2012). No entanto, nem sempre isso é possível, especialmente quando o pesquisador trabalha com muitos países e séries longitudinais mais longas.

Desde o pioneiro trabalho de Katz, Mair et. al. (1992), a queda no número de filiados aos partidos políticos vem sendo bem acompanhada na Europa Ocidental, sugerindo uma dificuldade das agremiações, na maior parte dos países analisados, em manter seus membros e recrutar novos. Dados recentes, compilados por Van Biezen, Mair e Poguntke (2012), mostram que houve uma queda de cinco pontos percentuais, em média, em 13 democracias consolidadas europeias nos últimos 30 anos. Nas 27 democracias analisadas na última rodada do estudo, a média de filiados por eleitores ficou em 4,7\%. França, Itália, Espanha e Estônia foram os únicos países que registraram crescimento entre os membros de partidos políticos.

A redução no número de filiados levantou a questão sobre as transformações qualitativas desse grupo. Quem são, atualmente, os filiados a partidos políticos? Eles se constituíram em um grupo muito distinto do restante da sociedade? Mudaram muito com relação aos membros que os partidos tinham antes?

Conforme argumentam Scarrow e Gezgor (2010), os filiados nunca foram um espelho da sociedade. Sempre estiveram acima da média na idade e nos níveis de renda e educação. Os membros sempre foram também, na sua maioria, homens e integrantes da classe média. Além disso, era comum estarem associados a sindicatos e grupos religiosos. Analisando dados recentes, os autores concluem que, com exceção da idade dos membros, que aumentou, o perfil sociodemográfico dos filiados não mudou muito nos últimos anos. No entanto, contrariando as expectativas, eles se mostraram menos ideológicos do que nos anos 1990 (SCARROW e GEZGOR, 2010).

As explicações para o declínio do número de filiados são muitas e não há um veredito final sobre o tema. Uma linha argumenta que os partidos políticos são, em si, estruturas em declínio no universo político (LAWSON e MERKL, 1988), o que ajudaria a compreender a redução do interesse dos cidadãos em participar deles. Outra argumenta que os partidos perderam incentivos em recrutar grandes contingentes de filiados com a modernização das campanhas eleitorais e dos meios de comunicação de massa. Os filiados teriam, assim, perdido o status de "embaixadores" das agremiações junto às suas comunidades e as lideranças não precisariam mais deles para atingir um grande número de eleitores (SCARROW, 1996). Em linha semelhante, autores como Katz e Mair (1995) e Whiteley (2011) sustentam que a aproximação dos partidos com relação ao Estado diminui os incentivos para as lideranças recrutarem novos membros. A lógica é 
simples: se os custos de manter o partido vêm do contribuinte, por que se esforçar em manter uma grande base de filiados? (WHITELEY, 2011). As evidências, porém, não se mostram conclusivas para nenhuma das linhas mencionadas aqui.

O segundo tema também está ligado ao relacionamento dos partidos com seus filiados: o processo decisório interno. Conforme aponta a literatura, está em curso, tanto em democracias estáveis quanto em novas, um processo de transferência de poder sobre a seleção de líderes partidários para o conjunto de filiados (SEYD e WHITELEY, 2002; KITTILSON e SCARROW, 2003; FREIDENBERG, 2005; SCARROW e GEZGOR, 2010; CROSS e BLAIS, 2012). De uma maneira geral, a literatura se refere a esse fenômeno como de "democratização interna" e, na maior parte dos casos, ele está ligado à crescente capacidade dos membros em participar diretamente (um filiado, um voto) dos processos de seleção de candidatos e lideranças e elaboração de propostas partidárias. A maior participação dos filiados nos processos decisórios intrapartidários reascendeu o debate a respeito da "Lei de Michels" sob novas bases teóricas e empíricas abertas pela maior quantidade de casos disponíveis para análise. Katz e Mair, em diferentes trabalhos, e dentro da perspectiva da emergência do modelo de partido cartel, defendem que o empowerment dos filiados representa uma falsa democratização, pois leva à ampliação do poder da liderança partidária. $\mathrm{O}$ argumento dos autores está baseado na premissa de que a massa desorganizada de filiados tende a apoiar a liderança partidária. Dessa forma, a "democratização interna", ao marginalizar as lideranças intermediárias e os ativistas, mais capazes de realizar oposição organizada, e ao fortalecer os membros comuns, acaba por produzir uma situação paradoxal na qual a maior participação da base resulta em maior poder e autonomia para a liderança (MAIR, 1994; KATZ e MAIR, 2002; 2009). Seyd e Whiteley, por exemplo, não concordam com essa interpretação. Em trabalhos sobre o Partido Trabalhista britânico refutam, a partir de evidências obtidas em surveys junto aos filiados e na análise dos resultados eleitorais internos, a premissa de que filiados menos ativos são mais "dóceis" e tendem a seguir a liderança. Segundo os autores, as evidências disponíveis na literatura não permitem afirmar claramente que a participação direta dos filiados resulta em inevitável fortalecimento do poder e da autonomia dos líderes partidários (SEYD, 1999; SEYD e WHITELEY, 2002).

Em uma perspectiva um pouco distinta, Kittilson e Scarrow argumentam que, independentemente da persistência de tendências "oligarquizantes" no interior das agremiações, a ampliação dos poderes do conjunto de filiados resulta no aumento do grau de transparência dos processos decisórios internos e da possibilidade dos cidadãos exercerem mais influência em um local onde importantes decisões são tomadas: os partidos políticos. (KITTILSON e SCARROW, 2003). Para os autores, assim como para Scarrow e Gezgor, a democratização no interior dos partidos seria também uma forma de atrair membros e enfrentar o crescente distanciamento entre eleitores e partidos 
verificado nas últimas décadas (KITTILSON e SCARROW, 2003; SCARROW e GEZGOR, 2010).

A análise do relacionamento dos partidos políticos com outras organizações da sociedade civil sempre foi um tema fundamental para a compreensão do desenvolvimento organizativo das agremiações políticas. Especialmente na experiência democrática europeia, os partidos utilizam as organizações (como sindicatos, grupos religiosos, etc.) como forma de criarem vínculos com setores do eleitorado. Em troca, fornecem o acesso à formulação de políticas públicas. Dessa maneira, as organizações da sociedade civil desempenham o papel de intermediários entre a sociedade e os partidos políticos e auxiliam na agregação de interesses.

Desde o início do século XX, os partidos estabeleceram diferentes tipos de vinculação com as organizações da sociedade civil e com diferentes graus de intensidade. As organizações podem ser totalmente independentes dos partidos, e sua associação estar vinculada à consecução de objetivos comuns, ou completamente vinculadas a eles, contando, inclusive, com uma superposição completa de membros e lideranças. Já com relação ao nível de intensidade, a literatura indica que o ápice da aproximação entre partidos políticos e organizações da sociedade civil aconteceu na "época de ouro" dos partidos de massa, entre os anos 20 e 60 do século passado. Desde então, a emergência do Estado de Bem-Estar e o processo de modernização socioeconômico agiram na erosão dos laços entre os partidos e grupos sociais específicos, levando a uma maior autonomia tanto dos partidos políticos quanto das próprias organizações da sociedade civil. Esse processo está no centro da emergência do partido de tipo catch all e, indiretamente, também do modelo de partido cartel (POGUNTKE, 2006; VERGE, 2012). Como vimos, para Katz e Mair (1995; 2009), os partidos políticos se aproximaram do Estado e se distanciaram da sociedade. Com recursos estatais garantidos, os incentivos para a manutenção de estreitos vínculos com organizações como sindicatos e associações religiosas diminuíram.

Recentemente, alguns trabalhos questionaram a interpretação unidirecional derivada da análise de Katz e Mair (1995; 2009), afirmando que o afastamento dos partidos com relação a outras organizações não é tão claro, além de não haver um padrão entre partidos ou países em torno desse fenômeno (POGUNTKE, 2002; ALLERN, AYLLOT, CHRISTIANSEN, 2007; VERGE, 2012). Allern, Ayllot e Christiansen, por exemplo, demonstram que o declínio no grau de aproximação entre os partidos e os sindicatos na Escandinávia não se deu de maneira uniforme. Na Suécia e na Noruega, os social-democratas mantiveram-se mais próximos dos sindicatos do que na Dinamarca. Os autores, articulando Escolha Racional e Institucionalismo Histórico, concluem que tanto o cálculo de custos e benefícios entre os atores envolvidos quanto a natureza dos vínculos construídos nas suas fases iniciais importam para explicar o grau de afastamento nos casos analisados (ALLERN, AYLLOT, CHRISTIANSEN, 2007). Em 
caminho semelhante, Christiansen (2012), em análise longitudinal sobre a relação entre grupos de interesse e partidos políticos de diferentes famílias ideológicas na Dinamarca, conclui que os laços se afrouxam quando os atores percebem que os custos em mantê-los excedem os benefícios. Segundo o autor, isso ajuda a explicar os diferentes padrões encontrados e as razões para eventuais aproximações após períodos de afastamento, colocando em xeque modelos mais estruturais, como o sugerido por Katz e Mair (1995). Em linha um pouco diferente, Verge demonstra como os partidos políticos espanhóis continuam interessados em desenvolver relações com organizações da sociedade civil. A autora, inclusive, faz interessante contribuição ao descrever como os partidos utilizam recursos estatais para construir redes de apoios envolvendo organizações da sociedade civil (CHRISTIANSEN, 2012).

Para encerrarmos, convém mencionarmos que Katz e Mair (2012) responderam, em recente texto, a algumas das críticas feitas ao modelo de partido cartel no que diz respeito às relações entre os partidos e as organizações da sociedade civil. Para os autores, o argumento geral continua a se sustentar quando as relações dos partidos com outros atores sociais no século XXI são comparadas com as mantidas pelos partidos dos anos 1950. No entanto, Katz e Mair reconhecem que novas democracias podem apresentar dinâmicas distintas e os partidos podem usar organizações da sociedade civil para fortalecerem suas posições frente ao eleitorado, desde que isso não signifique restrições as suas ações.

\section{A literatura sobre a organização dos partidos políticos brasileiros}

Em resenha feita no final dos anos 1990, Lima Jr. (1999) destacou a baixa produção acadêmica sobre a organização dos partidos políticos brasileiros. Escrevendo mais de uma década depois, Nicolau (2010) fez constatação semelhante. De fato, pouco sabemos como se estruturam os partidos políticos brasileiros que se organizaram desde o final do regime militar (1964-1985). Esta é uma situação que contrasta com os avanços verificados em outros temas da Ciência Política nacional, como a que aborda o próprio sistema partidário e a que trata das relações Executivo-Legislativo, para ficarmos apenas em algumas.

É possível distinguirmos a literatura que trata dos partidos políticos brasileiros sob uma perspectiva organizativa em dois blocos. O primeiro trata mais diretamente do Partido dos Trabalhadores (PT). O outro, dos demais grandes partidos. Na sua maioria, são estudos de caso realizados como dissertações de mestrado ou teses de doutorado. No primeiro grupo, destacam-se os trabalhos de Meneguello (1989), Keck (1991), Ribeiro (2010) e Amaral (2011). Meneguello e Keck escreveram textos clássicos sobre o PT e inauguraram uma interpretação a respeito das origens e dos primeiros anos do partido que persiste até hoje. É difícil encontrar qualquer trabalho de fôlego a respeito da agremiação que não mencione essas duas obras. Embora tenham algumas diferenças de enfoque e nível de 
detalhamento, os dois textos apontam para a singularidade do PT no seu processo de gestação: um partido criado de baixo para cima a partir da confluência de diversos atores sociais. Sindicalistas, membros da esquerda organizada, de setores progressistas da Igreja Católica e de movimentos sociais urbanos, assim como intelectuais e parlamentares do MDB, abraçaram a criação do PT e constituíram o seu DNA. Além da origem externa, as autoras ressaltam a preocupação do partido nos seus primeiros anos em construir um desenho institucional democrático que privilegiasse a participação das bases no seu processo decisório.

Ribeiro (2010) e Amaral (2011) seguem a tradição dos trabalhos de Meneguello (1989) e Keck (1991) e buscam analisar as transformações organizativas do PT. O trabalho de Ribeiro (2010) gira em torno de duas dimensões de análise: funcional e organizativa. Para o autor, o PT seguiu o caminho da social-democracia europeia, adquirindo características inequívocas de partido profissional-eleitoral como definido por Panebianco (2005) e se tornando cada vez mais dependente do Estado, aproximando-se também do modelo de partido cartel proposto por Katz e Mair $(1995 ; 2009)$. Muito bem documentada e com um percurso teórico claro, a análise de Ribeiro opta por enfatizar as semelhanças das transformações petistas com as descritas pela literatura a respeito da social-democracia europeia. Essa ênfase, porém, acaba diluindo as especificidades do caso petista e a importância da preservação de práticas e regras ao longo da história partidária, responsáveis também por moldar o seu desenvolvimento organizativo. Esse é um dos aspectos do trabalho de Amaral (2011) sobre as transformações do partido. O autor procura, ainda que sem a abrangência do trabalho de Ribeiro, requalificar as transformações pelas quais o partido passou entre 1995 e 2010, demonstrando que as mudanças na organização interna do PT refletem a acomodação da agremiação a uma posição que concilia sua história/origem com a necessidade de vencer eleições e governar.

Em uma perspectiva comparada, Roma (2006) e D'Araujo (2011) analisam alguns aspectos da organização do PT e do Partido da Social-Democracia Brasileira (PSDB). O primeiro demonstra como as origens e a ideologia de cada partido acabam por moldar seu comportamento e atuação. Nesse sentido, a origem parlamentar do PSDB acabou levando à criação de uma agremiação mais descentralizada e com menos interferência da burocracia partidária e dos filiados sobre suas lideranças do que no caso petista (ROMA, 2006). Já D'Araujo (2011) demonstra empiricamente que o PT está mais próximo de movimentos sociais e de setores do funcionalismo público do que o PSDB, o que acabou redundando em uma estratégia diferente de distribuição de cargos no governo Lula daquela verificada durante a presidência de Fernando Henrique Cardoso (FHC).

O segundo bloco é composto por trabalhos que, na sua maioria, tratam do PSDB, do Partido da Frente Liberal (PFL)/Democratas (DEM) e do Partido do Movimento Democrático Brasileiro (PMDB). Roma (2002) mostra como a estrutura organizativa do $\mathrm{PSDB}$ propiciou às lideranças partidárias tanto em 
âmbito nacional quanto estadual concretizar acordos com outras legendas sem terem que se submeter a constrangimentos de outras instâncias partidárias. Essa característica, segundo o autor, foi fundamental para o sucesso eleitoral da agremiação nos anos 1990 (ROMA, 2002). Em estudo no qual compara como distintos processos de formação e institucionalização partidárias podem contrabalançar os efeitos descentralizadores do federalismo, Ferreira mostra que o processo de formação do PMDB e de sua estruturação no período de transição para a democracia resultaram em um arranjo interno muito mais descentralizado do que o verificado no PFL/DEM, que desde a sua fundação contou com uma elite mais coesa e comprometida com a tarefa de fortalecer o partido no plano nacional (FERREIRA, 2002). As conclusões de Ferreira seguem as indicações de Kinzo (1988), que no final dos anos 1980 já apontara o exagerado facciosismo peemedebista. Em uma análise mais abrangente sobre o sistema partidário brasileiro, Mainwaring (2001) argumenta que PMDB, PFL/DEM e PSDB estão mais próximos do modelo catch all de partido e que suas estruturas são mais suscetíveis aos incentivos centrífugos do federalismo brasileiro do que as de partidos de esquerda, como o PT.

\section{Considerações Finais}

Neste texto, buscamos sistematizar a produção acadêmica e o conhecimento científico produzido no âmbito da Ciência Política, tanto nacional quanto internacional, sobre a organização dos partidos políticos. Discutimos a evolução dos modelos organizativos desde o pioneiro trabalho de Duverger (1980) até as mais recentes contribuições de Katz e Mair (1995; 2009) e Wolinetz (2002). Apresentamos também a produção mais contemporânea sobre processos decisórios internos e o relacionamento dos partidos com filiados e organizações da sociedade civil, bem como sobre a organização dos partidos políticos brasileiros.

No que diz respeito aos modelos de partidos, é possível perceber uma tensão entre os autores que acreditam em uma tendência evolutiva nas formas de organização partidária e aqueles que defendem ser difícil discernir uma direção inequívoca nas transformações organizativas verificadas ao longo do tempo. Essa tensão transparece, por exemplo, na discussão em torno do modelo de partido cartel, que vem dominando a literatura nos últimos 15 anos. De um lado, Katz e Mair reafirmam seus argumentos. De acordo com eles,

[...] nesses pouco mais de dez anos desde a publicação de nosso paper original, as tendências para as quais chamamos a atenção se tornaram ainda mais visíveis e fortaleceram nosso argumento. Isso é especialmente verdadeiro quando olhamos para os partidos tradicionais, que a cada dia estão mais próximos dos padrões que descrevemos tanto em termos organizativos quanto em termos competitivos (KATZ e MAIR, 2009, p. 759-760). 
Para os autores, o processo de cartelização dos sistemas políticos tem consequências perigosas para o próprio regime democrático, pois os partidos não conseguem mais preencher o espaço de representação e agregação de interesses, abrindo lacunas para lideranças populistas e agremiações "antipartidos" (KATZ e MAIR, 2009).

A visão mais pessimista de Katz e Mair, embora tenha estabelecido uma importante agenda de pesquisa nos últimos anos, não é completamente aceita por muitos estudiosos dos partidos políticos. A lógica evolutiva enunciada pelos autores é questionada dentro de uma crítica mais geral sobre a construção de modelos analíticos para a compreensão das transformações partidárias. Como pudemos ver, autores como Wolinetz (2002) e Krouwel (2006), diante de uma série de evidências empíricas, não se mostram plenamente convencidos de que os partidos caminham inexoravelmente na mesma direção. Já Dalton, Farrell e McAllister (2011) argumentam que os partidos, apesar de todas as transformações pelas quais passaram, ainda conseguem realizar as funções de conexão entre a sociedade e o governo e de mobilização política dos cidadãos. Ou seja, continuam a ser fundamentais para o funcionamento das democracias contemporâneas e permanecem como atores essenciais no processo de controle dos governantes pelos cidadãos (DALTON, FARRELL e MCALLISTER, 2011). Os autores reconhecem, porém, que as dinâmicas democráticas mais recentes estabecem novos desafios aos partidos, como a emergência de lideranças carismáticas antipartidárias e de práticas de democracia direta. No entanto, os autores indicam que nenhuma forma de organização política, até o presente, mostrou-se superior aos partidos políticos para viabilizar a competição política nas democracias contemporâneas e que, historicamente, as agremiações políticas vêm demonstrando uma impressionante habilidade de se adaptar e superar os desafios encontrados.

Por fim, cabe levantarmos uma agenda de pesquisa para o caso brasileiro. Como vimos, apesar de boas monografias e artigos sobe a organização de alguns partidos, como o PT e o PSDB, e alguns estudos comparados, ainda há muito a descobrir sobre como as agremiações políticas surgidas no Brasil no atual período democrático selecionam lideranças e candidatos, administram suas finanças, tomam decisões, se relacionam com movimentos sociais e outras organizações da sociedade civil e envolvem militantes em suas atividades.

Diante desse quadro, é fundamental desenvolvermos trabalhos que minorem as lacunas existentes na literatura. Para isso, são necessárias pesquisas que combinem sólida abordagem empírica com uma análise refinada envolvendo os principais partidos do País. Um importante passo será dado com um duplo esforço investigativo: (a) Mapear o desenvolvimento organizativo dos principais partidos políticos do País; (b) Descobrir quem são os filiados aos partidos políticos no Brasil, o que pensam, como participam das atividades partidárias e a quais redes de associação pertencem. 
Com relação ao primeiro, entendemos que a elaboração de um banco de dados sobre a organização dos principais partidos do País durante o período democrático ainda precisa ser feito. Esse banco deve conter informações sobre estatutos, número de filiados, número de diretórios, atividades realizadas pelos partidos (como reuniões, encontros, congressos e conferências), recursos financeiros e lideranças partidárias (membros de diretórios e listas de candidatos).

Outra lacuna importante no estudo dos partidos políticos no Brasil está justamente no que toca ao conhecimento daqueles que integram os partidos. Os dados existentes mais recentes, na sua maioria, dão conta apenas de altas lideranças ou lideranças intermediárias (ROMA, 2006; RIBEIRO, 2010; AMARAL, 2011; D’ARAUJO, 2011). Não sabemos nada além da localização geográfica sobre os filiados aos partidos políticos. A realização de uma pesquisa sobre esse universo pode abrir uma avenida de descobertas importantes sobre os partidos e os níveis de participação política no Brasil.

Oswaldo E. do Amaral é Professor do Departamento de Ciência Política da Universidade Estadual de Campinas (UNICAMP) e pesquisador do Centro de Estudos de Opinião Pública (CESOP) da Unicamp. E-mail: oswamaral@gmail.com

\section{Referências}

ALLERN, Elin; AYLLOT, Nicholas; CHRISTIANSEN, Flemming. Social Democrats and trade unions in Scandinavia: The decline and persistence of institutional relationships. European Journal of Political Research, Oxford, v. 46, p. 607-635, 2007.

AMARAL, Oswaldo E. do. Adaptação e resistência: o PT no Governo Lula entre 2003 e 2008. Revista Brasileira de Ciência Política, n. 4, 2010, p. 105-134.

Ainda conectado: o PT e seus vínculos com a sociedade. Opinião Pública, Campinas, v. 17, n. 1, p. 1-44, 2011.

BRYCE, James. Modern Democracies. New York: Macmillan, 1921 apud WHITE, John Kenneth. What is a political party? In: KATZ, Richard; CROTTY, William (Ed.). Handbook of Party Politics. London: Sage, 2006.

CHRISTIANSEN, Flemming. Organizational de-integration of political parties and interest groups in Denmark. Party Politics, London, v. 18, n. 1, p. 27-43, 2012.

CROSS, William; BLAIS, André. Who selects the party leader? Party Politics, London, v. 18, n. 2, p. 127-150, 2012. 
DALTON, Russell; FARRELL, David; McAlLISTER, Ian. Political Parties and Democratic Linkage: How Parties Organize Democracy. Oxford: OUP, 2011.

D'ARAUJO, Maria Celina. PSDB e PT e o Poder Executivo. Desigualdade e Diversidade, Rio de Janeiro, Dossiê Especial, p. 65-100, 2011.

DUVERGER, Maurice. Os Partidos Políticos. Rio de Janeiro: Zahar/UnB, 1980.

FERREIRA, Denise Paiva. PFL $x$ PMDB: marchas e contramarchas (1982-2000). Goiânia: Alternativa, 2002.

FREIDENBERG, Flavia. Mucho ruido y pocas nueces. Organizaciones partidistas y democracia interna en América Latina. Polis: Investigación y Análisis Sociopolítico y Psicosocial, Iztapalapa, v. 1, n. 1, p. 91-134, 2005.

HARMEL, Robert. Party Organizational Change: Competing Explanations? In: LUTHER, Kurt Richard; ROMMEL, Ferdinand Müller (ed.). Political Parties in the New Europe: Political and Analytical Challenges. Oxford: OUP, 2002. p. 119-142.

HARMEL, Robert; JANDA, Kenneth. An integrated theory of party goals and party change. Journal of Theoretical Politics, Los Angeles, v. 6, n. 3, p. 259287, 1994.

JANDA, Kenneth; KING, Desmond. Formalizing and testing Duverger's theories on political parties. Comparative Political Studies, Washington, v. 18, n. 2, p. 139-169, 1985.

KATZ, Richard; MAIR, Peter. The Evolution of Party Organizations in Europe: The Three Faces of Party Organization. The American Review of Politics, Fayetteville, v. 14, p. 593-617, winter, 1993.

(ed.). How Parties Organize: Change and Adaptation in Party Organizations in Western Democracies. London: Sage, 1994.

- Changing Models of Party Organization and Party Democracy: The Emergence of the Cartel Party. Party Politics, London, v. 1, n. 1, p. 5-28, 1995. The Ascendancy of the Party in Public Office: Party Organizational Change in Twentieth-Century Democracies. In: GUNTHER, Richard; MONTERO, José Ramón; LINZ, Juan (ed.). Political Parties: Old Concepts and New Challenges. Oxford: OUP, 2002. p. 113-135.

The Cartel Party Thesis: A Restatement. Perspectives on Politics, Bloomington, v. 7, n. 4, p. 753-766, 2009.

Parties, interest groups and cartels: A comment. Party Politics, London, v. 18, n. 1, p. 107-111, 2012.

KATZ, Richard; MAIR, Peter et. al. The Membership of Political Parties in European Democracies, 1960-1990. European Journal of Political Research, Amsterdam, n. 22, p. 329-345, 1992.

KECK, Margaret E. PT - a lógica da diferença: o Partido dos Trabalhadores na construção da democracia brasileira. São Paulo: Ática, 1991.

KINZO, Maria D'Alva. Oposição e autoritarismo: gênese e trajetória do MDB, 1966-1979. São Paulo: Vértice, 1988. 
KIRCHHEIMER, Otto. The Transformation of the Western European Party Systems. In: LAPALOMBARA, Joseph; WEINER, Myron (ed.). Political Parties and Political Development. Princeton: PUP, 1966. p. 177-200.

KITTILSON, Miki; SCARROW, Susan. Political Parties and the Rhetoric and Realities of Democratization. In: CAIN, Bruce; DALTON, Russel; SCARROW, Susan (ed.). Democracy Transformed? Expanding Political Opportunities in Advanced Industrial Democracies. Oxford: OUP, 2003.

KROUWEL, André. Party models. In: KATZ, Richard; CROTTY, William (ed.). Handbook of Party Politics. London: Sage, 2006. p. 249-269.

LAWSON, Kay; MERKL, Peter (ed.). When Parties Fail: Emerging Alternative Organizations. Princeton: PUP, 1988.

LIMA JR., Olavo Brasil. Partidos, eleições e Poder Legislativo. In: MICELI, Sérgio (org.). O que ler na Ciência Social brasileira: Política. São Paulo: Sumaré, 1999. p. 13-57.

MAINWARING, Scott. Sistemas partidários em novas democracias: o caso do Brasil. Rio de Janeiro: FGV, 2001.

MAIR, Peter. Party Organizations: From Civil Society to the State. In: KATZ, Richard; MAIR, Peter (ed.). How Parties Organize: Change and Adaptation in Party Organizations in Western Democracies. London: Sage, 1994.

MENEGUELLO, Rachel. PT: A formação de um partido, 1979-1982. São Paulo: Paz e Terra, 1989.

MICHELS, Robert. Sociologia dos Partidos Políticos. Brasília: UNB, 1982.

NICOLAU, Jairo. Partidos e Sistemas Partidários: 1985-2009. In: LESSA, Renato (org.). Horizontes das Ciências Sociais no Brasil: Ciência Política. São Paulo: Barcarolla, 2010. p. 217-240.

PANEBIANCO, Angelo. Modelos de partido: organização e poder nos partidos políticos. São Paulo: Martins Fontes, 2005.

POGUNTKE, Thomas. Party Organizational Linkage: Parties Without Firm Social Roots? In: LUTHER, Kurt Richard; ROMMEL, Ferdinand Müller (ed.). Political Parties in the New Europe: Political and Analytical Challenges. Oxford: OUP, 2002. p. 43-62.

. Political Parties and Other Organizations. In: KATZ, Richard; CROTTY, William (ed.). Handbook of Party Politics. London: Sage, 2006.

ROMA, Celso. A institucionalização do PSDB entre 1988 e 1999. Revista Brasileira de Ciências Sociais, São Paulo, v. 17, n. 49, p. 71-92, 2002.

. Organizaciones de partido en Brasil: El PT y el PSDB bajo perspectiva comparada. América Latina Hoy, Salamanca, n. 44, p. 153-184, 2006.

RIBEIRO, Pedro. Dos sindicatos ao governo: a organização nacional do PT entre 1980 e 2005. São Carlos: EdUFScar, 2010.

SAMUELS, David; SHUGART, Matthew. Presidents, Parties, and Prime Ministers: How the Separation of Powers Affects Party Organization and Behavior. Cambridge: CUP, 2010. 
SCARROW, Susan. Parties and Their Members. Oxford: OUP, 1996.

SCARROW, Susan; GEZGOR, Burcu. Declining memberships, changing members? European political party members in a new era. Party Politics, London, v. 16, n. 6, p. 823-843, 2010.

SEYD, Patrick. New Parties/New Politics?: A case study of the British Labour Party. Party Politics, London, v. 5, n. 3, p. 383-405, 1999.

SEYD, Patrick; WHITELEY, Paul. High-Intensity Participation: The Dynamics of Party Activism in Britain. Ann Harbor: UMP, 2002.

STROM, Kaare. A behavioral Theory of Competitive Political Parties. American Journal of Political Science, Houston, v. 34, n. 2, p. 565-598, 1990.

STROM, Kaare; MULLER, Wolfgang (ed.). Policy, office or votes? how political parties in Western Europe make hard decisions. Cambridge: CUP, 1999.

VAN BIEZEN, Ingrid; MAIR, Peter; POGUNTKE, Thomas. Going, going,..gone? The decline of party membership in contemporary Europe. European Journal of Political Research, Oxford, v. 51, p. 24-56, 2012.

VERGE, Tània. Party strategies towards civil society in new democracies: The Spanish case. Party Politics, London, v. 18, n. 1, p. 45-60, 2012.

WARE, Alan. Political Parties and Party Systems. Oxford: OUP, 1996.

WHITELEY, Paul. Is the party over? The decline of party activism and membership across the democratic world. Party Politics, London, v. 17, n. 1, p. 21-44, 2011.

WOLINETZ, Steven. Beyond the Catch-All Party: Approaches to the Study of Parties and Party Organization in Contemporary Democracies. In: GUNTHER, Richard; MONTERO, Jose; LINZ, Juan. Political Parties: Old Concepts, New Challenges. Oxford: OUP, 2002. p. 136-165. 